https://helda.helsinki.fi

Chronotype in very low birth weight adults - a sibling study

Björkqvist, Johan

2020-07-02

Björkqvist, J , Kuula , J , Kuula , L, Nurhonen, M , Hovi , P , Räikkönen , K, Pesonen , A \& Kajantie , E 2020 , ' Chronotype in very low birth weight adults - a sibling study ' , Chronobiology International , vol. 37 , no. 7 , pp. 1023-1033 . https://doi.org/10.1080/07420528.2020.1754847

http://hdl.handle.net/10138/329528

https://doi.org/10.1080/07420528.2020.1754847

acceptedVersion

Downloaded from Helda, University of Helsinki institutional repository.

This is an electronic reprint of the original article.

This reprint may differ from the original in pagination and typographic detail.

Please cite the original version. 


\section{Chronotype in very low birth weight adults - a sibling study}

Johan Björkqvist* MD PhD, ${ }^{\text {a,b }}$ Juho Kuula MD, ${ }^{\text {bc }}$ Liisa Kuula PhD, ${ }^{\text {d }}$ Markku Nurhonen MSc, ${ }^{b}$ Petteri Hovi MD PhD, ${ }^{\mathrm{a}, \mathrm{b}}$ Katri Räikkönen PhD, ${ }^{\mathrm{e}}$ Anu Pesonen PhD, ${ }^{\mathrm{d}}$ Eero Kajantie MD $\mathrm{PhD}{ }^{\mathrm{a}, \mathrm{b}, \mathrm{f}, \mathrm{g}}$

${ }^{\text {a} C h i l d r e n ' s ~ H o s p i t a l, ~ a n d ~ P e d i a t r i c ~ R e s e a r c h ~ C e n t e r, ~ U n i v e r s i t y ~ o f ~ H e l s i n k i ~ a n d ~ H e l s i n k i ~}$ University Hospital, Helsinki, Finland.

${ }^{\mathrm{b}}$ Department of Public Health Promotion, Finnish Institute for Health and Welfare, Helsinki, Finland.

${ }^{\mathrm{c}}$ Department of Radiology, HUS Medical Imaging Center, University of Helsinki and Helsinki University Hospital, Helsinki, Finland.

${ }^{\mathrm{d} S}$ SleepWell Research Program, Faculty of Medicine, University of Helsinki, Finland. eDepartment of Psychology and Logopedics, Faculty of Medicine, University of Helsinki. ${ }^{f}$ PEDEGO research unit, University of Oulu, Oulu, Finland.

gDepartment of Clinical and Molecular Medicine, Norwegian University of Science and Technology, Trondheim, Norway.

*Corresponding author:

Johan Björkqvist. johan.bjorkqvist@ helsinki.fi. National Institute for Health and Welfare, Mannerheimintie 166 C, Post box 30, 00270, Helsinki, Finland. Telephone: +358 29524 6000 .

Short title: Chronotype in VLBW adults

\section{Word count:}

Abstract: $\mathbf{2 4 3}$ words

Main text (Introduction, Materials and methods, Results, Discussion): 3326 words

Sources of financial assistance: Drs Björkqvist and Juho Kuula have received salary from the Doctoral Programme in Clinical Research, University of Helsinki. Dr Liisa Kuula has received a research grant from the Academy of Finland. Academy of Finland (Grants 274794 and 315680 to Eero Kajantie, 1322035 and 12871741 to Anu Pesonen); the European Commission (Horizon2020 award 733280 RECAP Research on Children and Adults Born Preterm); the Finnish Foundation for Pediatric Research; Finska Läkaresällskapet; the Juho Vainio Foundation; the Novo Nordisk Foundation; the Signe and Ane Gyllenberg Foundation; the Sigrid Jusélius Foundation; and the Yrjö Jahnsson Foundation.

The other authors have indicated that they have no financial relationships relevant to this article to disclose.

\footnotetext{
Abbreviations:

AGA: Appropriate for gestational age

ELBW: Extremely low birth weight, $\leq 1500$ grams

FMBR: Finnish Medical Birth Registry

HeSVA: Helsinki Study of Very low birth weight Adults

MSFsc: Midsleep on free days, corrected for sleep debt

SGA: Small for gestational age, $\leq-2 \mathrm{SD}$

VLBW: Very low birth weight, $\leq 1500$ grams

WASO: Wake after sleep onset
} 


\begin{abstract}
Chronotype is the temporal preference for activity and sleep during the $24 \mathrm{~h}$ day and is linked to mental and physical health, quality of life, and mortality. Later chronotypes, so called "night owls", consistently display poorer health outcomes than "larks". Previous studies have suggested that preterm birth ( $<37$ weeks of gestation) is associated with an earlier chronotype in children, adolescents, and young adults, but studies beyond this age are absent. Our aim was to determine if adults born preterm at very low birth weight (VLBW, $\leq 1500$ grams) display different chronotypes than their siblings. We studied VLBW adults, aged 29.9 years (SD 2.8), matched with same-sex term-born siblings as controls. A total of 123 participants, consisting of 53 sibling pairs and 17 unmatched participants, provided actigraphy-derived data on the timing, duration, and quality of sleep from 1640 nights (mean 13.3 per participant, SD 2.7). Mixed effects models provided estimates and significance tests. Compared to their siblings, VLBW adults displayed 27 min earlier sleep midpoint during free days (95\% CI: 3 to 51 min, $\mathrm{p}=.029)$. This was also reflected in timing of falling asleep, waking up, and sleepdebt corrected sleep midpoint. The findings were emphasized in VLBW participants born small for gestational age. VLBW adults displayed an earlier chronotype than their siblings still at age 30, which suggests that the earlier chronotype is an enduring individual trait not explained by shared family factors. This preference could provide protection from risks associated with preterm birth.
\end{abstract}

Keywords: actigraphy, sleep midpoint, midsleep, MSFsc, VLBW, very low birth weight, preterm, prematurity 


\section{Introduction}

Preterm birth is globally the main cause of death in children under five years (Liu et al. 2016). Although most prematurely born children survive without severe disabilities (March of Dimes et al. 2012), a disruptive start to life may leave long-lasting effects. Decades-long follow-up studies on preterm survivors with very or extremely low birth weight (VLBW $\leq 1500$ grams, ELBW $\leq 1000$ grams) show increased blood pressure (Hovi et al. 2016), dysglycaemia (Hovi et al. 2007; Morrison et al. 2016), less exercise (Kajantie et al. 2010), more anxiety (Mathewson et al. 2017), and more internalizing (Pyhälä et al. 2017). Interestingly, in the field of chronobiology, some of these vulnerabilities are displayed by people with late chronotypes, so called night owls (Anothaisintawee et al. 2017; Merikanto et al. 2013; Hisler et al. 2017; Taylor and Hasler 2018). Chronotype is the partly heritable (37-50\%, Koskenvuo et al. 2007; Watson et al. 2013) preference in timing for activity or sleep; it is a behavioral manifestation of the internal circadian clock, and it impacts most aspects of human life, from DNA repair (Sancar et al. 2010) and physiology (Pilorz et al. 2018) to personality and behavior (Adan et al. 2012; Fabbian et al. 2016). The resemblance in outcomes of preterm survivors and night owls has generated studies investigating whether chronotype contributes to prematurity-related morbidity. Counterintuitively, studies have suggested an earlier chronotype in extremely preterm children (Stangenes et al. 2017), preterm adolescents (Hibbs et al. 2014), and VLBW preterm adults in their early twenties (Strang-Karlsson et al. 2010; Björkqvist et al. 2014), but not in a young adult cohort with subjects from all degrees of prematurity (Björkqvist, Pesonen, et al. 2018). Thus, current evidence is inconclusive whether the reported earlier chronotype of preterm survivors persists into adulthood.

We investigated whether adult VLBW survivors, aged on average 30 years, display an earlier chronotype in a sibling design, which allows better control for heritability and familial environment than case-control studies. This is important because VLBW young 
adults initiate independent lives later than term-born controls (Kajantie et al. 2008), and report more protective upbringing (Pyhälä et al. 2011), which can affect sleep-wake patterns (Randler et al. 2009). To answer these questions, we measured sleep patterns of VLBW survivors and their siblings with actigraphy for two weeks.

\section{Materials and methods}

\section{Recruitment}

We recruited VLBW subjects from the Helsinki Study of Very Low Birth Weight Adults (HeSVA, Hovi et al. 2007), the ESTER Preterm Birth Study (Sipola-Leppänen et al. 2015), and through the Finnish Medical Birth Registry (FMBR). HeSVA includes 166 VLBW survivors treated 1978-85 at the neonatal intensive care unit of the Children's Hospital at Helsinki University Central Hospital (Figure 1, map, supplemental), who underwent clinical examinations 2004-05. ESTER includes 376 preterm subjects (55 VLBW) either from the Northern Finland Birth Cohort 1986 (NFBC1986, born 1985-86) or identified through the Finnish Medical Birth Register (FMBR; born 1987-89), who underwent clinical examinations 2009-11. Subjects in NFBC1986 undergo regular assessments, so to avoid participation fatigue we only recruited subjects born 1987-89. After recruitments from HeSVA and ESTER, we identified through the FMBR VLBW survivors from live births between 1.1.1987-30.9.1990 in hospitals serving the provinces of Uusimaa, Varsinais-Suomi, and Northern Häme/Pirkanmaa, and physicians from these birth hospitals contacted the subjects.

The aim was to recruit 80 sibling pairs for three-day testing, including MRI scans, metabolic tests, tissue biopsies, exercise tests, neurocognitive assessment, and accelerometry. In power calculations 80 pairs, given $1-\beta=.8$ and $\alpha=.05$, allow detection of effect sizes of 0.32 in two-way comparisons (Faul et al. 2007). 
Between July 2014 and February 2017, we successfully contacted 186 VLBW adults (Figure 2) whose population records indicated having a same-sex sibling born within 10 years. If records indicated a multiple birth, we randomly contacted one survivor. If willing to participate, each VLBW adult sought participation of a sibling with the least age difference. The term-born, same-sex sibling had to be 18 years of age or older, with less than 10 years age difference. If either potential participant presented with pregnancy, cerebral palsy, mental retardation, motor or sensory impairment, or endocrine disorder, we excluded both. Sixty-four potential pairs (34.4\% of contacted) declined participation and $43(23.1 \%)$ warranted exclusion, so the recruitment process netted 79 sibling pairs (42.5\%): 22 via HeSVA, 6 via ESTER and 51 via FMBR. Participation analysis was possible with pseudonymized registry data (FMBR, ESTER) and previously collected data from HeSVA. For all variables in Table 2 and three-tiered parental education (lower secondary or less or unknown, upper secondary, tertiary) the 79 participants differed from the 175 non-participants only in less maternal smoking during pregnancy $(\mathrm{p}=0.009)$ and more highly educated fathers $(\mathrm{p}=0.004$, Table 1 , supplemental).

Three sibling-controls dropped out of the clinical studies, performed 2014-17, and 8 subjects declined actigraphy participation (Figure 3). One VLBW subject's exclusion criterion became apparent at the clinical visit, and scrutiny of birth records revealed 4 siblings born preterm, which warranted their exclusion. Of the 142 actigraphy participants, 19 (13.4\%) returned invalid measurements due to technical errors or non-compliance, leaving 123 participants with analyzable data (53 pairs, 17 unmatched participants). These participants did not differ significantly from the 27 study participants without actigraphy data regarding sex distribution, age, gestational age, birth weight, or relative birth weight (in standard deviation units, based on population statistics according to sex and gestational age). 
Perinatal data for HeSVA and ESTER participants has been previously collected from hospital or maternity clinic records (Hovi et al. 2007; Sipola-Leppänen et al. 2015). For their siblings and all new subjects we similarly collected data about birth weight, gestational age, parity, mother's age, maternal smoking during pregnancy, and multiple pregnancy. Our primary source for gestational age was the noted weeks on birth certificate or records. If it differed by over two weeks from gestational age derived from last menstrual period we checked whether it was due to ultrasonography correction, which it was in all cases. Based on sex and gestational age, Pihkala et al.'s (1989) standards converted birth weight into standard deviation units, with small for gestational age (SGA) defined as $\leq-2 \mathrm{SD}$, as opposed to appropriate for gestational age $(>-2 \mathrm{SD}$ and $<+2 \mathrm{SD}, \mathrm{AGA})$.

The study followed accepted ethical practices (Portaluppi et al. 2010), the ethics committee of the Hospital District of Helsinki and Uusimaa approved the study, and all participants provided informed signed consent. Participants completing the study received 84 EUR reimbursement per visit, plus travel costs and overnight lodging if required.

\section{Sleep measurement}

Wrist-worn accelerometers called actigraphs (Actiwatch2, Philips-Respironics, Murrysville, PA) measured sleep with 1-minute epochs and medium sensitivity setting. Both siblings received instructions to wear the device simultaneously for at least 14 days and to report in a diary sleep times, work hours, use of alcohol or sleeping medication, temporary removals of the device, and abnormal occurrences like illnesses or travel. To help recognize these situations the participants kept sleep logs and pressed an event marker on the device, which showed up on the recording.

Actigraphy is the most appropriate tool for objectively measuring sleep-wake patterns in non-laboratory settings due to its minimal invasiveness, good validity, and ease of 
use (Van De Water et al. 2011). Actigraphs measure sleep timing and duration accurately, but tend to misclassify wake (Pesonen and Kuula 2018). The technology in Actiwatch2 is based on piezo-electric sensors that detect movement, which the device stores as activity counts. Based on these counts, an algorithm (Respironics Actiware v5.59) analyzed the data and scored each minute as wake or sleep.

The 123 participants recorded 1726 nights, of which $86(5.0 \%)$ had to be excluded based on technical criteria: (a) the actigraph was not used; (b) bedtime information was missing; (c) sleep data indicated the participant was already asleep at the self-reported time; or (d) self-reported awakening time was missing and the activity pattern was ambiguous. The final accepted nights numbered 1640 (participant mean 13.3, SD 2.7). Participants reported use of alcohol in 272 cases, sleeping medication in 37, and daytime naps in 49. Parents reported being woken up by children during 74 nights. Three participants reported ailments more disruptive than the common cold, which was our cut-off point for labelling illness. Self-reported free- or workday status for next morning was available for 1396 nights (85.1\%), and we assumed free weekend mornings for 242 nights (14.9\%). We excluded 11 nights with shift work. Free day comparisons were available for 51 pairs (VLBW $n=59$, control $=60)$, and work day comparisons for 47 pairs $(\operatorname{VLBW~} n=61$, control $=56$ ).

The main outcome for chronotype was free day sleep midpoint, because sleep is constrained during workdays. Sleep midpoint is the half-way time between falling asleep and waking up, and it serves as proxy for dim light melatonin onset (Terman et al. 2001), the gold standard of circadian markers (Klerman et al. 2002). A further refinement is free day sleep midpoint corrected for sleep debt, MSFsc $=$ free day sleep midpoint $-0.5^{*}($ free day sleep duration - average weekly sleep duration) (Roenneberg et al. 2004), because sleep deprivation accrued during work days manifests itself on free days as longer sleep duration and later sleep midpoint. 
We also report: sleep start, when the participant fell asleep; sleep end, when the participant woke up; duration, time between sleep start and end; actual sleep time, time spent asleep after sleep start; wake after sleep onset (WASO), time spent awake after sleep start; wake percentage, proportion of duration that is awake; catch-up sleep, difference in sleep duration between free and work days, indicating possible sleep debt; and social jet lag, difference in sleep midpoint between free and work days (Wittmann et al. 2006) or difference in sleep start between free and work days (Jankowski 2017).

\section{Statistical analysis}

We assessed background variables on a group level with independent samples t-tests and $\chi^{2}$, and pairs with paired t-tests and McNemar's test. We used linear mixed effects models to study if VLBW status explained potential group differences in sleep outcomes, with repeated measurements nested within subjects, and subjects nested within families. The following variables were fixed effects: model 1 included the minimal chronobiological variables of age and sex (Roenneberg et al. 2007), and model 2 further adjusted for use of alcohol and sleep medication, naps, child-related awakenings, and illness. Unmatched subjects remained in the analysis to improve model accuracy.

Calculation of MSFsc, catch-up sleep, and social jet lag involves mean values from work and free days. For these outcomes, we 1) excluded nights with preceding naps, alcohol use, or sleep medication use to omit their effect, 2) calculated mean values separately for free and work days, 3) computed MSFsc, catch-up sleep, and social jet lag, and 4) compared outcomes with paired t-test. This exclusion process caused attrition, leaving 41 pairs for comparisons of MSFsc, catch-up sleep, and social jet lag.

We performed different post hoc mixed effects analyses to the free day sleep midpoint (model 2). To test for possible effect of relative birth weight on sleep outcomes we 
compared separately VLBW SGA and AGA subgroups to their AGA siblings. We also examined possible sex interaction with a sex*VLBW interaction term and ran the analysis separately according to sex. Further, we examined if birth or testing season (Vollmer et al. 2012; Didikoglu et al. 2019) influenced the VLBW-control difference in free day sleep midpoint. This was done by introducing photoperiod variables to model 2 (spring [Feb-April], summer [May-July], autumn [Aug-Oct], and winter [Nov-Jan]). Finally, as a sensitivity analysis we excluded subjects who had participated in the earlier HeSVA $(\mathrm{n}=19)$ and $\operatorname{ESTER}(n=3)$ studies.

We performed all statistical analyses using SPSS (IBM SPSS Statistics for Windows, version 22.0. Armonk, NY: IBM Corp). We rounded time differences to minutes in the text for brevity, but the tables also display seconds. 


\section{Results}

The VLBW subjects $(\mathrm{n}=63)$ were on average 29.9 (SD 2.8) years old, and the siblings 29.7 years (SD 5.2, $\mathrm{n}=60$, Table 2). Men comprised 50.8\% of VLBW and $48.3 \%$ of control participants. Of the 53 whole sibling pairs 26 were men (49.1\%). Besides having a lower birth weight, a larger proportion of VLBW subjects were born SGA (36.5\% vs 3.3\%), and from a multiple pregnancy $(11.1 \%$ vs $1.7 \%)$. No differences emerged between groups for mother's age at delivery, maternal smoking during pregnancy, or being firstborn.

On free days the VLBW subjects displayed significantly earlier chronotype than their siblings, as evidenced by the earlier sleep midpoint (-27 min, $\mathrm{p}=.029$, Table 3 , model 2), sleep start (-25 min, $\mathrm{p}=.040)$, and sleep end $(-28 \mathrm{~min}, \mathrm{p}=.043)$. No differences in sleep duration, actual sleep time, WASO, or wake percentage emerged on free days.

On work days sleep timing did not differ between groups. Although not statistically significant, the VLBW subjects displayed 22 min earlier sleep start $(\mathrm{p}=.108), 18$ min longer duration $(\mathrm{p}=.068)$, and $11 \mathrm{~min}$ longer actual sleep time $(\mathrm{p}=.197)$. The VLBW subjects displayed more WASO (6 min, $\mathrm{p}=.023)$, for a wake percentage difference of $1.06 \%$ $(\mathrm{p}=.05)$

VLBW subjects displayed 41 min earlier MSFsc than their siblings (95\% CI: 78 to -5 minutes, $\mathrm{p}=.029$, not in tables). No difference emerged for catch-up sleep ( 0 min, 95\% CI: -31 to $31 \mathrm{~min}$ ) or social jet lag (sleep midpoint difference $-20 \mathrm{~min}, 95 \% \mathrm{CI}$ : -51 to 10 min, sleep start difference $-20 \mathrm{~min}, 95 \% \mathrm{CI}:-52 \mathrm{~min}$ to $12 \mathrm{~min}$ ).

For post hoc analysis we separately compared free day sleep midpoint of VLBW SGA $(n=21)$ and VLBW AGA $(n=38)$ subjects to their siblings born AGA $(n=58,50$ complete pairs [19 SGA, 31 AGA]). This revealed a stronger tendency for earlier chronotype in the VLBW SGA group (-48 min, $95 \%$ CI: -75 to $-21 \mathrm{~min}, \mathrm{p}=.001$, model 2 , Figure 4 ) than in the VLBW AGA group (-21 min, 95\% CI: -52 to $10 \mathrm{~min}, \mathrm{p}=.18)$. The sex interaction term 
introduced to free day sleep midpoint model 2 was not statistically significant, but analysis by sex revealed that free day sleep midpoint in the VLBW group was more pronounced among women $(-41 \mathrm{~min}, 95 \% \mathrm{CI}$ : -6 to $-76 \mathrm{~min}, \mathrm{p}=0.023)$ than among men $(-15$ min earlier, $95 \%$ CI: -49 to $21 \mathrm{~min}, \mathrm{p}=0.4$ ). Addition of birth or testing season shifted the free day sleep midpoint difference by less than a minute, so our results remained. Exclusion of previous HeSVA and ESTER participants from the analysis did not meaningfully impact our finding.

\section{Discussion}

Our study is the first to compare VLBW subjects' chronotype and sleep to that of their termborn siblings. The analysis revealed clear differences in sleep timing on free days, and subtle differences on work days. First, on free mornings the earlier sleep start, midpoint, sleep end, and the earlier sleep-debt-corrected midpoint MSFsc suggest that VLBW adults displayed an earlier chronotype than their term-born siblings. Second, on work mornings with more forced schedules both groups woke up at similar times, but VLBW subjects possibly went to bed earlier (sleep start -22 min, $\mathrm{p}=.108$, sleep duration $18 \mathrm{~min}, \mathrm{p}=.068$ ). This anticipation of a scheduled early morning might explain why VLBW subjects displayed 6 min more WASO during work nights.

Our findings align well with previous studies in children, adolescents, and younger adults. However, direct comparisons are often difficult due to diversity of subject age and outcomes; only few studies have reported sleep midpoints or MSFsc. The strongest support comes from a large actigraphy study of preterm adolescents (mean birth weight 1514 grams, gestational age 31 weeks), which showed 24 min earlier sleep midpoint during weekends (Hibbs et al. 2014), compared to $27 \mathrm{~min}$ in the current study. Other actigraphy studies also show earlier sleep start or sleep end among VLBW young adults and toddlers (Strang-Karlsson et al. 2007; Asaka and Takada 2010; Björkqvist et al. 2014). One overnight 
polysomnography study on very preterm (<32 weeks) school-aged children showed 13 min earlier sleep onset (Maurer et al. 2016), but an earlier study by the same team found sleep onset was non-significantly 6 min earlier (Perkinson-Gloor et al. 2015). The current findings were in disagreement with a study of only 33 VLBW subjects covering the entire preterm range, which did not discover difference in chronotype between preterm and term-born groups (Björkqvist, Pesonen, et al. 2018). The phenomenon of an earlier chronotype may, therefore, be restricted to those born smallest.

Supporting this notion, a post hoc analysis by relative birth weight revealed much earlier chronotype (free day sleep midpoint -48 min, $p=0.001$ ) in VLBW subjects born SGA. Possible developmental programming would arguably be strongest among those most exposed to impaired intrauterine environments, and the combined pathology of prematurity and SGA is stronger than either condition alone (Katz et al. 2013). However, the association between intrauterine growth and chronotype remains inconclusive: Strang-Karlsson et al. (2010) found pronounced self-evaluated morningness in VLBW young adults born AGA rather than SGA. Although the sex interaction was not statistically significant, we found a more pronounced difference among women than among men. While this is an interesting finding, it is post hoc and should be confirmed in further studies.

Compared to night owls, larks display better mental and physical health (Adan et al. 2012; Fabbian et al. 2016), higher academic achievement (Tonetti et al. 2015) and quality of life (Prieto et al. 2012; Suh et al. 2017), and reduced mortality (Knutson and von Schantz 2018). Thus, a natural assumption is that earlier chronotype might be a protective factor. Paradoxically, the reported difference could also be a consequence of developmental programming due to fetal distress. Several animal studies indicate that early life exposure to stress (Koehl et al. 1997; Koehl et al. 1999), hypoxia (Joseph et al. 2002), malnutrition (Durán et al. 2005), alcohol (Handa et al. 2007), or postnatal continuous lighting (Brooks et al. 2014) 
also might advance the internal clock, so confirming possible protective effects requires further study. It is possible the chronotype of the mother may be transferred through an imprinting signal caused by maternal circadian melatonin pattern in utero (Serón-Ferré et al. 2012) and during breastfeeding (McKenna and Reiss 2018). If so, preterm birth could disrupt this transfer.

Our study had several strengths. Using siblings as controls not only increased statistical power but allowed circumvention of unmeasured family-based confounders. Also, the mean recording period of almost two weeks is, to our knowledge, unparalleled in this field. Furthermore, the detailed information about free and work days allowed determination of unforced circadian rhythms. As weaknesses we note that over $13 \%$ of participants failed to return valid measurements, which is unfortunate because minimal drop-out was important due to the delicate study setting. Also, the family environment might have changed during the decade that we allowed as age difference between siblings, and we lacked detailed information about family composition and changes in living conditions and location. We placed strong emphasis in recruiting whole sibling pairs, which may lead to selective participation of behaviorally similar sibling pairs. This would, if anything, lead to more conservative findings.

Adults born preterm at VLBW display an earlier chronotype than their siblings at almost 30 years of age. This indicates that the phenomenon persists with age and more independent living and seems most pronounced after disruptive perinatal conditions, such as VLBW and SGA. Although this study reports robust results, the actual explanation of this phenomenon remains elusive. We suggest future studies investigate possible mechanisms, such as differences in light exposure, personality type, length of the internal day, or possible genetic variation or epigenetic modification of clock genes. Our findings should also be replicated in other parts of the world in order to determine whether regional or cultural 
differences in sleep timing play any part in explaining these results. These mechanisms may shed light to early life programming of chronotype and to potential protective factors in children and adults born preterm.

\section{Declaration of interest}

The authors report no conflict of interest. 


\section{References}

Adan A, Archer SN, Hidalgo MP, Di Milia L, Natale V, Randler C. 2012. Circadian Typology: A Comprehensive Review. Chronobiol Int. 29(9):1153-1175.

Anothaisintawee T, Lertrattananon D, Thamakaison S, Knutson KL, Thakkinstian A, Reutrakul S. 2017. Later chronotype is associated with higher hemoglobin A1c in prediabetes patients. Chronobiol Int. 34(3):393-402.

Asaka Y, Takada S. 2010. Activity-based assessment of the sleep behaviors of VLBW preterm infants and full-term infants at around 12 months of age. Brain Dev. 32(2):150-155.

Björkqvist J, Hovi P, Pesonen A-K, Räikkönen K, Heinonen K, Järvenpää A-L, Eriksson JG, Andersson S, Kajantie E. 2018. Adults who were born preterm with a very low birth weight reported a similar health-related quality of life to their term-born peers. Acta Paediatr. 107(2):354-357.

Björkqvist J, Paavonen J, Andersson S, Pesonen A-K, Lahti J, Heinonen K, Eriksson J, Räikkönen K, Hovi P, Kajantie E, Strang-Karlsson S. 2014. Advanced sleep-wake rhythm in adults born prematurely: confirmation by actigraphy-based assessment in the Helsinki Study of Very Low Birth Weight Adults. Sleep Med. 15(9):1101-1106.

Björkqvist J, Pesonen A-K, Kuula L, Matinolli H-M, Lano A, Sipola-Leppänen M, Tikanmäki M, Wolke D, Järvelin M-R, Eriksson JG, et al. 2018. Premature birth and circadian preference in young adulthood: evidence from two birth cohorts. Chronobiol Int. 35(4):555-564.

Brooks E, Patel D, Canal MM. 2014. Programming of Mice Circadian Photic Responses by Postnatal Light Environment. PLOS ONE. 9(5):e97160.

Didikoglu A, Maharani A, Payton A, Pendleton N, Canal MM. 2019. Longitudinal change of sleep timing: association between chronotype and longevity in older adults. Chronobiol Int. 36(9):12851300.

Durán P, Cintra L, Galler JR, Tonkiss J. 2005. Prenatal protein malnutrition induces a phase shift advance of the spontaneous locomotor rhythm and alters the rest/activity ratio in adult rats. Nutr Neurosci. 8(3):167-172.

Fabbian F, Zucchi B, De Giorgi A, Tiseo R, Boari B, Salmi R, Cappadona R, Gianesini G, Bassi E, Signani F, et al. 2016. Chronotype, gender and general health. Chronobiol Int. 33(7):863-882.

Faul F, Erdfelder E, Lang A-G, Buchner A. 2007. G*Power 3: A flexible statistical power analysis program for the social, behavioral, and biomedical sciences. Behav Res Methods. 39(2):175-191.

Handa RJ, Zuloaga DG, McGivern RF. 2007. Prenatal ethanol exposure alters core body temperature and corticosterone rhythms in adult male rats. Alcohol. 41(8):567-575.

Hibbs AM, Storfer-Isser A, Rosen C, levers-Landis CE, Taveras EM, Redline S. 2014. Advanced Sleep Phase in Adolescents Born Preterm. Behav Sleep Med. 12(5):412-424.

Hisler GC, Phillips AL, Krizan Z. 2017. Individual Differences in Diurnal Preference and Time-ofExercise Interact to Predict Exercise Frequency. Ann Behav Med. 51(3):391-401. 
Hovi P, Andersson S, Eriksson JG, Järvenpää A-L, Strang-Karlsson S, Mäkitie O, Kajantie E. 2007. Glucose regulation in young adults with very low birth weight. N Engl J Med. 356(20):2053-2063.

Hovi P, Vohr B, Ment LR, Doyle LW, McGarvey L, Morrison KM, Evensen KAl, van der Pal S, Grunau RE, Brubakk A-M. 2016. Blood pressure in young adults born at very low birth weight. Hypertension. 68:880-887.

Jankowski KS. 2017. Social jet lag: Sleep-corrected formula. Chronobiol Int. 34(4):531-535.

Joseph V, Mamet J, Lee F, Dalmaz Y, Van Reeth O. 2002. Prenatal hypoxia impairs circadian synchronisation and response of the biological clock to light in adult rats. J Physiol. 543(1):387-395.

Kajantie E, Hovi P, Raikkonen K, Pesonen A-K, Heinonen K, Järvenpää A-L, Eriksson JG, Strang-Karlsson S, Andersson S. 2008. Young Adults With Very Low Birth Weight: Leaving the Parental Home and Sexual Relationships--Helsinki Study of Very Low Birth Weight Adults. Pediatrics. 122(1):e62-e72.

Kajantie E, Strang-Karlsson S, Hovi P, Räikkönen K, Pesonen A-K, Heinonen K, Järvenpää A-L, Eriksson JG, Andersson S. 2010. Adults Born at Very Low Birth Weight Exercise Less than Their Peers Born at Term. J Pediatr. 157(4):610-616.e1.

Katz J, Lee AC, Kozuki N, Lawn JE, Cousens S, Blencowe H, Ezzati M, Bhutta ZA, Marchant T, Willey BA, et al. 2013. Mortality risk in preterm and small-for-gestational-age infants in low-income and middleincome countries: a pooled country analysis. The Lancet. 382(9890):417-425.

Kent AL, Wright IMR, Abdel-Latif ME, the New South Wales and Australian Capital Territory Neonatal Intensive Care Units Audit Group. 2012. Mortality and Adverse Neurologic Outcomes Are Greater in Preterm Male Infants. Pediatrics. 129(1):124-131.

Klerman EB, Gershengorn HB, Duffy JF, Kronauer RE. 2002. Comparisons of the Variability of Three Markers of the Human Circadian Pacemaker. J Biol Rhythms. 17(2):181-193.

Knutson KL, von Schantz M. 2018. Associations between chronotype, morbidity and mortality in the UK Biobank cohort. Chronobiol Int. 35(8):1045-1053.

Koehl M, Barbazanges A, Le Moal M, Maccari S. 1997. Prenatal stress induces a phase advance of circadian corticosterone rhythm in adult rats which is prevented by postnatal stress. Brain Res. 759(2):317-320.

Koehl M, Darnaudéry M, Dulluc J, Reeth OV, Moal ML, Maccari S. 1999. Prenatal stress alters circadian activity of hypothalamo-pituitary-adrenal axis and hippocampal corticosteroid receptors in adult rats of both gender. J Neurobiol. 40(3):302-315.

Koskenvuo M, Hublin C, Partinen M, Heikkilä K, Kaprio J. 2007. Heritability of diurnal type: a nationwide study of 8753 adult twin pairs. J Sleep Res. 16(2):156-162.

Liu L, Oza S, Hogan D, Chu Y, Perin J, Zhu J, Lawn JE, Cousens S, Mathers C, Black RE. 2016. Global, regional, and national causes of under-5 mortality in 2000-15: an updated systematic analysis with implications for the Sustainable Development Goals. The Lancet. 388(10063):3027-3035.

March of Dimes, PMNCH, Save the children, WHO. 2012. Born too soon: the global action report on preterm birth [Internet]. Howson C, Kinney M, Lawn JE, editors. Geneva: World Health Organization.; 
[accessed 2017 Dec 29]. http://www.who.int/pmnch/media/news/2012/201204\%5Fborntoosoonreport.pdf

Mathewson KJ, Chow CHT, Dobson KG, Pope El, Schmidt LA, Van Lieshout RJ. 2017. Mental health of extremely low birth weight survivors: A systematic review and meta-analysis. Psychol Bull. 143(4):347-383.

Maurer N, Perkinson-Gloor N, Stalder T, Hagmann-von Arx P, Brand S, Holsboer-Trachsler E, Wellmann S, Grob A, Weber P, Lemola S. 2016. Salivary and hair glucocorticoids and sleep in very preterm children during school age. Psychoneuroendocrinology. 72:166-174.

McKenna H, Reiss IKM. 2018. The case for a chronobiological approach to neonatal care. Early Hum Dev. 126:1-5.

Merikanto I, Lahti T, Puolijoki H, Vanhala M, Peltonen M, Laatikainen T, Vartiainen E, Salomaa V, Kronholm E, Partonen T. 2013. Associations of Chronotype and Sleep With Cardiovascular Diseases and Type 2 Diabetes. Chronobiol Int. 30(4):470-477.

Morrison KM, Ramsingh L, Gunn E, Streiner D, Van Lieshout R, Boyle M, Gerstein H, Schmidt L, Saigal S. 2016. Cardiometabolic Health in Adults Born Premature With Extremely Low Birth Weight. Pediatrics. 138(4):e20160515-e20160515.

Perkinson-Gloor N, Hagmann-von Arx P, Brand S, Holsboer-Trachsler E, Grob A, Weber P, Lemola S. 2015. The role of sleep and the hypothalamic-pituitary-adrenal axis for behavioral and emotional problems in very preterm children during middle childhood. J Psychiatr Res. 60:141-147.

Pesonen A-K, Kuula L. 2018. The Validity of a New Consumer-Targeted Wrist Device in Sleep Measurement: An Overnight Comparison Against Polysomnography in Children and Adolescents. J Clin Sleep Med. 14(04):585-591.

Pihkala J, Hakala T, Voutilainen P, Raivio K. 1989. [Characteristic of recent fetal growth curves in Finland]. Duodecim Lääketieteellinen Aikakauskirja. 105(18):1540-1546.

Pilorz V, Helfrich-Förster C, Oster H. 2018. The role of the circadian clock system in physiology. Pflüg Arch - Eur J Physiol. 470(2):227-239.

Portaluppi F, Smolensky MH, Touitou Y. 2010. Ethics and Methods for Biological Rhythm Research on Animals and Human Beings. Chronobiol Int. 27(9-10):1911-1929.

Prieto PD, Díaz-Morales JF, Barreno CE, Mateo MJC, Randler C. 2012. Morningness-Eveningness and Health-Related Quality of Life among Adolescents. Span J Psychol. 15(2):613-623.

Pyhälä R, Räikkönen K, Pesonen A-K, Heinonen K, Lahti J, Hovi P, Strang-Karlsson S, Andersson S, Eriksson JG, Järvenpää A-L, Kajantie E. 2011. Parental Bonding after Preterm Birth: Child and Parent Perspectives in the Helsinki Study of Very Low Birth Weight Adults. J Pediatr. 158(2):251-256.e1.

Pyhälä R, Wolford E, Kautiainen H, Andersson S, Bartmann P, Baumann N, Brubakk A-M, Evensen KAI, Hovi P, Kajantie E, et al. 2017. Self-Reported Mental Health Problems Among Adults Born Preterm: A Meta-analysis. Pediatrics. 139(4):e20162690.

Randler C, Bilger S, Díaz-Morales JF. 2009. Associations among Sleep, Chronotype, Parental Monitoring, and Pubertal Development among German Adolescents. J Psychol Prov. 143(5):509-20. 
Roenneberg T, Kuehnle T, Juda M, Kantermann T, Allebrandt K, Gordijn M, Merrow M. 2007. Epidemiology of the human circadian clock. Sleep Med Rev. 11(6):429-438.

Roenneberg T, Kuehnle T, Pramstaller PP, Ricken J, Havel M, Guth A, Merrow M. 2004. A marker for the end of adolescence. Curr Biol. 14(24):R1038-R1039.

Sancar A, Lindsey-Boltz LA, Kang T-H, Reardon JT, Lee JH, Ozturk N. 2010. Circadian clock control of the cellular response to DNA damage. FEBS Lett. 584(12):2618-2625.

Serón-Ferré M, Mendez N, Abarzua-Catalan L, Vilches N, Valenzuela FJ, Reynolds HE, Llanos AJ, Rojas A, Valenzuela GJ, Torres-Farfan C. 2012. Circadian rhythms in the fetus. Mol Cell Endocrinol. 349(1):68-75.

Sipola-Leppänen M, Vääräsmaki M, Tikanmäki M, Matinolli H-M, Miettola S, Hovi P, Wehkalampi K, Ruokonen A, Sundvall J, Pouta A, et al. 2015. Cardiometabolic Risk Factors in Young Adults Who Were Born Preterm. Am J Epidemiol. 181(11):861-873.

Stangenes KM, Fevang SK, Grundt J, Donkor HM, Markestad T, Hysing M, Elgen IB, Bjorvatn B. 2017. Children born extremely preterm had different sleeping habits at 11 years of age and more childhood sleep problems than term-born children. Acta Paediatr. 106(12):1966-1972.

Strang-Karlsson S, Kajantie E, Pesonen A-K, Räikkönen K, Hovi P, Lahti J, Heinonen K, Järvenpää A-L, Eriksson JG, Andersson S, Paavonen EJ. 2010. Morningness propensity in young adults born prematurely: The Helsinki Study of Very Low Birth Weight Adults. Chronobiol Int. 27(9-10):18291842.

Strang-Karlsson S, Raikkonen K, Kajantie E, Andersson S, Hovi P, Heinonen K, Pesonen A-K, Järvenpää A-L, Eriksson JG, Paavonen EJ. 2007. Sleep Quality in Young Adults with Very Low Birth Weight--the Helsinki Study of Very Low Birth Weight Adults. J Pediatr Psychol. 33(4):387-395.

Suh S, Yang H-C, Kim N, Yu JH, Choi S, Yun C-H, Shin C. 2017. Chronotype Differences in Health Behaviors and Health-Related Quality of Life: A Population-Based Study Among Aged and Older Adults. Behav Sleep Med. 15(5):361-376.

Taylor BJ, Hasler BP. 2018. Chronotype and Mental Health: Recent Advances. Curr Psychiatry Rep. 20(8):59.

Terman JS, Terman M, Lo E-S, Cooper TB. 2001. Circadian Time of Morning Light Administration and Therapeutic Response in Winter Depression. Arch Gen Psychiatry. 58(1):69-75.

Tonetti L, Natale V, Randler C. 2015. Association between circadian preference and academic achievement: A systematic review and meta-analysis. Chronobiol Int. 32(6):792-801.

Van De Water ATM, Holmes A, Hurley DA. 2011. Objective measurements of sleep for non-laboratory settings as alternatives to polysomnography - a systematic review. J Sleep Res. 20(1pt2):183-200.

Vollmer C, Christoph Randler, Milia LD. 2012. Further Evidence for the Influence of Photoperiod at Birth on Chronotype in a Sample of German Adolescents. Chronobiol Int. 29(10):1345-1351.

Watson NF, Buchwald D, Harden KP. 2013. A twin study of genetic influences on diurnal preference and risk for alcohol use outcomes. J Clin Sleep Med. 9(12):1333-1339. 
Wittmann M, Dinich J, Merrow M, Roenneberg T. 2006. Social Jetlag: Misalignment of Biological and Social Time. Chronobiol Int. 23(1-2):497-509. 


\section{Figure legends}

Figure 1. Map of recruitment areas

Figure 2. Flowchart of participant recruitment

Figure 3. Flowchart of actigraphy participants

Figure 4. Mean difference and 95\% confidence interval of free day sleep midpoint of very low birth weight $(\mathrm{VLBW})$ adults born small for gestation age $(\leq-2 \mathrm{SD}, \mathrm{SGA}, \mathrm{n}=21)$ and appropriate for gestational age ( $>-2 \mathrm{SD}$ and $<+2 \mathrm{SD}, \mathrm{AGA}, \mathrm{n}=38)$ compared to term siblings born AGA $(\mathrm{n}=58)$. Complete pairs numbered $\mathrm{n}=50$ (19 SGA, 31 AGA). 


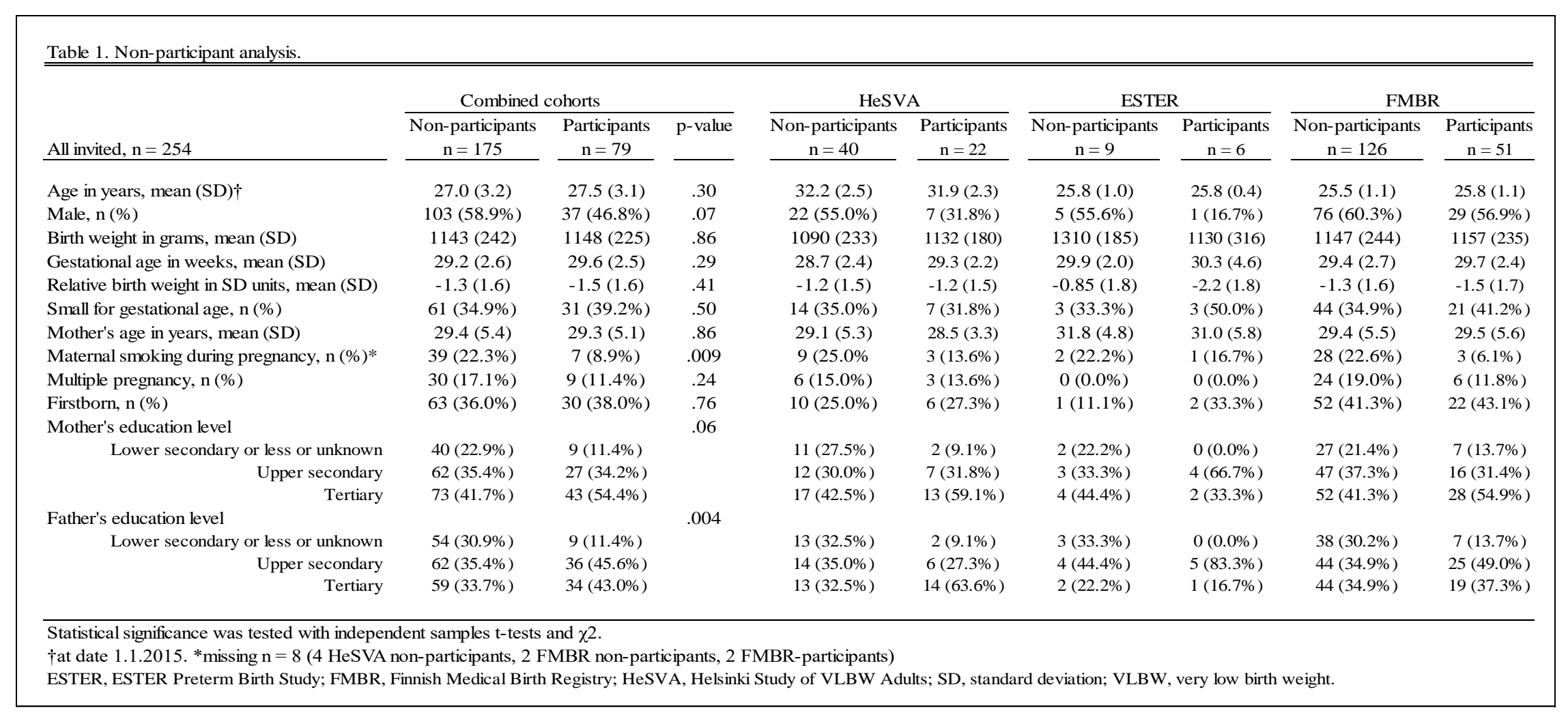


Table 2. Background characteristics of the study groups

All participants, $\mathrm{n}=123$

Age in years, mean (SD)

Male, n (\%)

Birth weight in grams, mean (SD)

Gestational age in weeks, mean (SD)

Relative birth weight in SD units, mean (SD)

Small for gestational age, $\mathrm{n}(\%)$

Mother's age in years, mean (SD)

Maternal smoking during pregnancy $\dagger, \mathrm{n}(\%)$

Multiple pregnancy, n (\%)

Firstborn, n (\%)

Complete pairs, $\mathrm{n}=106$

Age in years, mean (SD)

Male, n (\%)

Birth weight in grams, mean (SD)

Gestational age in weeks, mean (SD)

Relative birth weight in SD units, mean (SD)

Small for gestational age, $\mathrm{n}(\%)$

Mother's age in years, mean (SD)

Maternal smoking during pregnancy $\dagger, \mathrm{n}(\%)$

Multiple pregnancy, n (\%)

Firstborn, n (\%) $\underline{\text { VLBW, } n=63} \underline{\text { Sibling, } n=60}$

$29.9(2.8) \quad 29.7(5.2)$

$32(50.8 \%) \quad 29(48.3 \%)$

$1135(217) \quad 3391(452) * *$

$29.4(2.4) \quad 39.7(1.3)^{* * *}$

$-1.4(1.6) \quad-0.3(1.0) * *$

$23(36.5 \%) \quad 2(3.3 \%) * *$

$29.9(4.9) \quad 29.9(5.0)$

$9(14.3 \%) \quad 9(15.0 \%)$

$7(11.1 \%) \quad 1(1.7 \%)^{*}$

$22(34.9 \%) \quad 20(33.3 \%)$

$\underline{\text { VLBW, } \mathrm{n}=53 \quad \text { Sibling, } \mathrm{n}=53}$

$29.8(2.9) \quad 29.8(5.3)$

$26(49.1 \%) \quad 26(49.1 \%)$

$1144(208) \quad 3406(459) * *$

$29.6(2.4) \quad 39.7(1.3) * *$

$-1.5(1.5) \quad-0.3(1.0) * *$

$21(39.6 \%) \quad 1(1.9 \%) * *$

$30.0(5.1) \quad 30.1(4.9)$

$7(13.2 \%) \quad 8(15.1 \%)$

$7(13.2 \%) \quad 1(1.9 \%) * *$

$20(37.7 \%) \quad 17(32.1 \%)^{*}$

$\dagger$ data missing for VLBW $\mathrm{n}=2$ and sibling $\mathrm{n}=9, * \mathrm{p}<.05, * * \mathrm{p}<.01$

VLBW, very low birth weight; SD, standard deviation. 
Table 3. Comparison of sleep variables. Mean values (SD) in control siblings are presented with mean differences $(95 \% \mathrm{CI})$ between the VLBW and siblingcontrols. Negative values denote earlier or shorter time in the VLBW group.

\begin{tabular}{|c|c|c|}
\hline \multirow[b]{3}{*}{ Sibling, h:min } & Free morning & Work morning \\
\hline & \multicolumn{2}{|l|}{ Sleep midpoint } \\
\hline & 4:39 am (1:55) & $3: 22$ am (1:39) \\
\hline VLBW, min:s, model 1 & $-26: 03(-51: 59 \text { to }-00: 08)^{*}$ & $-12: 55(-38: 46$ to $12: 56)$ \\
\hline \multirow[t]{2}{*}{2} & $-26: 50(-50: 45 \text { to }-02: 54)^{*}$ & $-12: 19(-37: 01$ to $12: 23)$ \\
\hline & \multicolumn{2}{|l|}{ Start time } \\
\hline Sibling, h:min & 12:36 am (2:01) & $11: 42 \mathrm{pm}(1: 42)$ \\
\hline$\overline{\text { VLBW, min:s, model } 1}$ & $-25: 04(-52: 49$ to $02: 41)$ & $-22: 39(-50: 13$ to $04: 55)$ \\
\hline \multirow[t]{2}{*}{2} & $-25: 24(-49: 38 \text { to }-01: 09)^{*}$ & $-21: 36(-48: 01$ to $04: 50)$ \\
\hline & \multicolumn{2}{|l|}{ End time } \\
\hline Sibling, h:min & 8:43 am (2:05) & 7:02 am (1:56) \\
\hline \multirow{3}{*}{$\begin{array}{l}\text { VLBW, min:s, model } 1 \\
2\end{array}$} & $-26: 33(-54: 15$ to $01: 09)$ & $-03: 14$ (-30:58 to $24: 29)$ \\
\hline & $-27: 47(-54: 44 \text { to }-00: 51)^{*}$ & $-03: 05$ (-29:41 to $23: 30)$ \\
\hline & \multicolumn{2}{|l|}{ Duration } \\
\hline Sibling, h:min & 8:07 (1:30) & $7: 19(1: 32)$ \\
\hline \multirow{3}{*}{$\begin{array}{r}\overline{\text { VLBW, min:s, model } 1} \\
2\end{array}$} & $-02: 00(-22: 10$ to $18: 11)$ & $18: 37$ (-00:38 to $37: 52)$ \\
\hline & $-02: 31(-21: 41$ to $16: 40)$ & $17: 44(-01: 21$ to $36: 50)$ \\
\hline & \multicolumn{2}{|l|}{ Actual sleep time } \\
\hline Sibling, h:min & $7: 16(1: 21)$ & $6: 36(1: 20)$ \\
\hline$\overline{\text { VLBW, min:s, model } 1}$ & $-06: 10(-23: 54$ to $11: 34)$ & $11: 45(-05: 15$ to $28: 45)$ \\
\hline \multirow[t]{2}{*}{2} & $-07: 01(-24: 46$ to $10: 44)$ & $11: 02(-05: 54$ to $27: 58)$ \\
\hline & \multicolumn{2}{|l|}{ Wake after sleep onset } \\
\hline Sibling, min:s & 50:49 (24:20) & 43:41 (21:31) \\
\hline \multirow{3}{*}{ VLBW, min:s, model 1} & $04: 57(-01: 43$ to $11: 36)$ & $06: 24$ (00:55 to $11: 53)^{*}$ \\
\hline & 05:01 (-01:30 to $11: 32)$ & $06: 15(00: 54 \text { to } 11: 35)^{*}$ \\
\hline & \multicolumn{2}{|l|}{ Wake percentage } \\
\hline Sibling, percent & $10.4(4.3)$ & $9.8(3.8)$ \\
\hline$\overline{\mathrm{LBW}, \text { percent, model } 1}$ & $0.93(-0.34$ to 2.20$)$ & $1.07(-0.02$ to 2.16$)$ \\
\hline 2 & $0.96(-0.30$ to 2.22$)$ & $1.06(0.00 \text { to } 2.12)^{*}$ \\
\hline \multirow{2}{*}{\multicolumn{3}{|c|}{$\begin{array}{l}* \mathrm{p}<.05 . \text { Linear mixed effect models provided estimates and significance tests. } \\
\text { Free day comparisons were available for } 51 \text { pairs }(\mathrm{VLBW} n=59, \text { control }=60) \text {, } \\
\text { and workday comparisons for } 47 \text { pairs (VLBW } \mathrm{n}=61, \mathrm{control}=56 \text { ). }\end{array}$}} \\
\hline & & \\
\hline \multicolumn{3}{|c|}{ Model 1 adjusts for sex and age. } \\
\hline \multicolumn{3}{|c|}{$\begin{array}{l}\text { Model } 2 \text { further adjusts for use of alcohol, sleep medication, naps, child-related } \\
\text { awakenings, and illness. }\end{array}$} \\
\hline CI, confidence interval; & , standard deviation; VLB & very low birth weight. \\
\hline
\end{tabular}




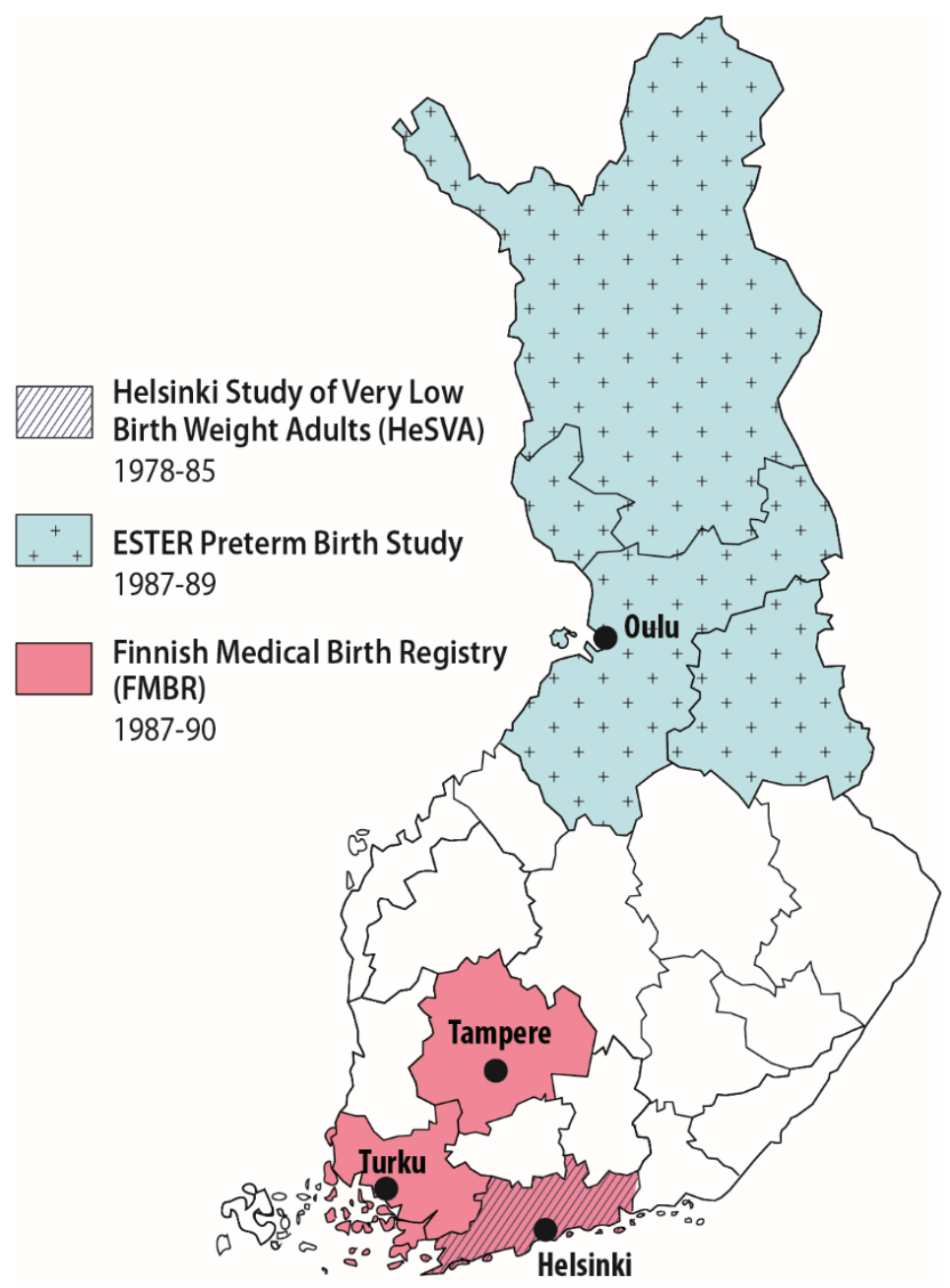

Figure 1 


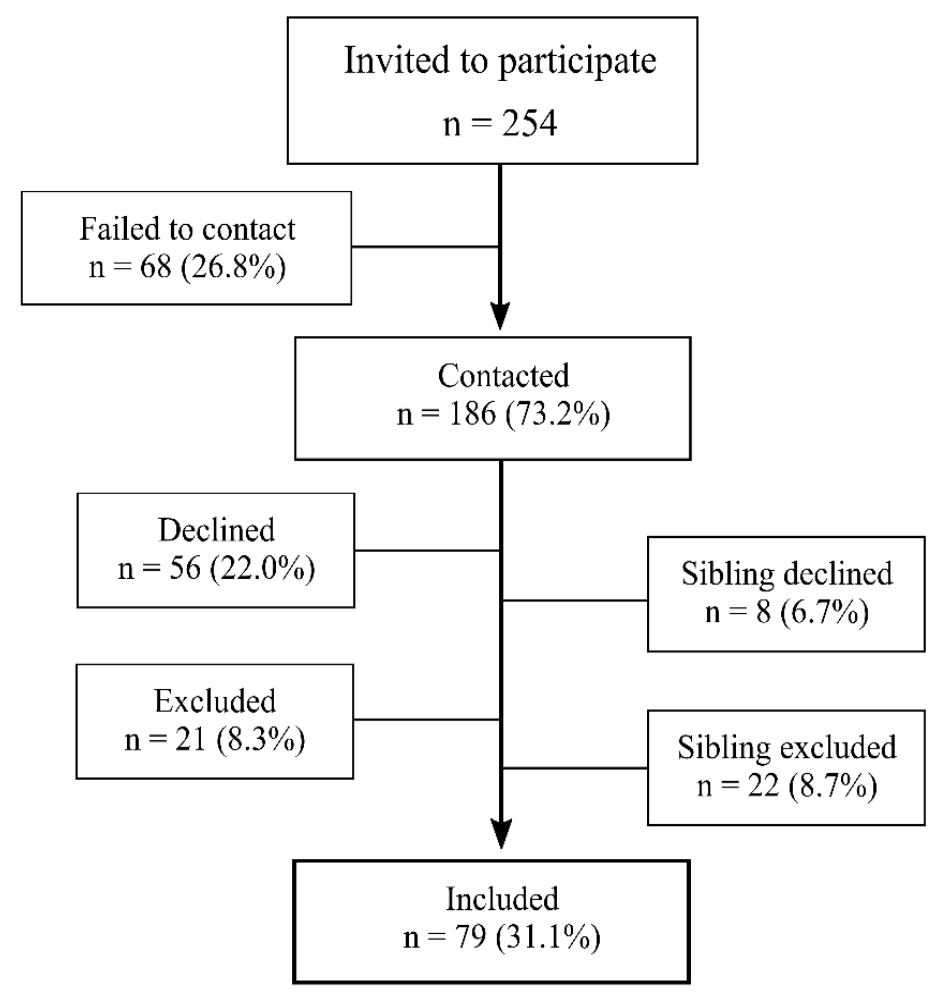


Figure 3

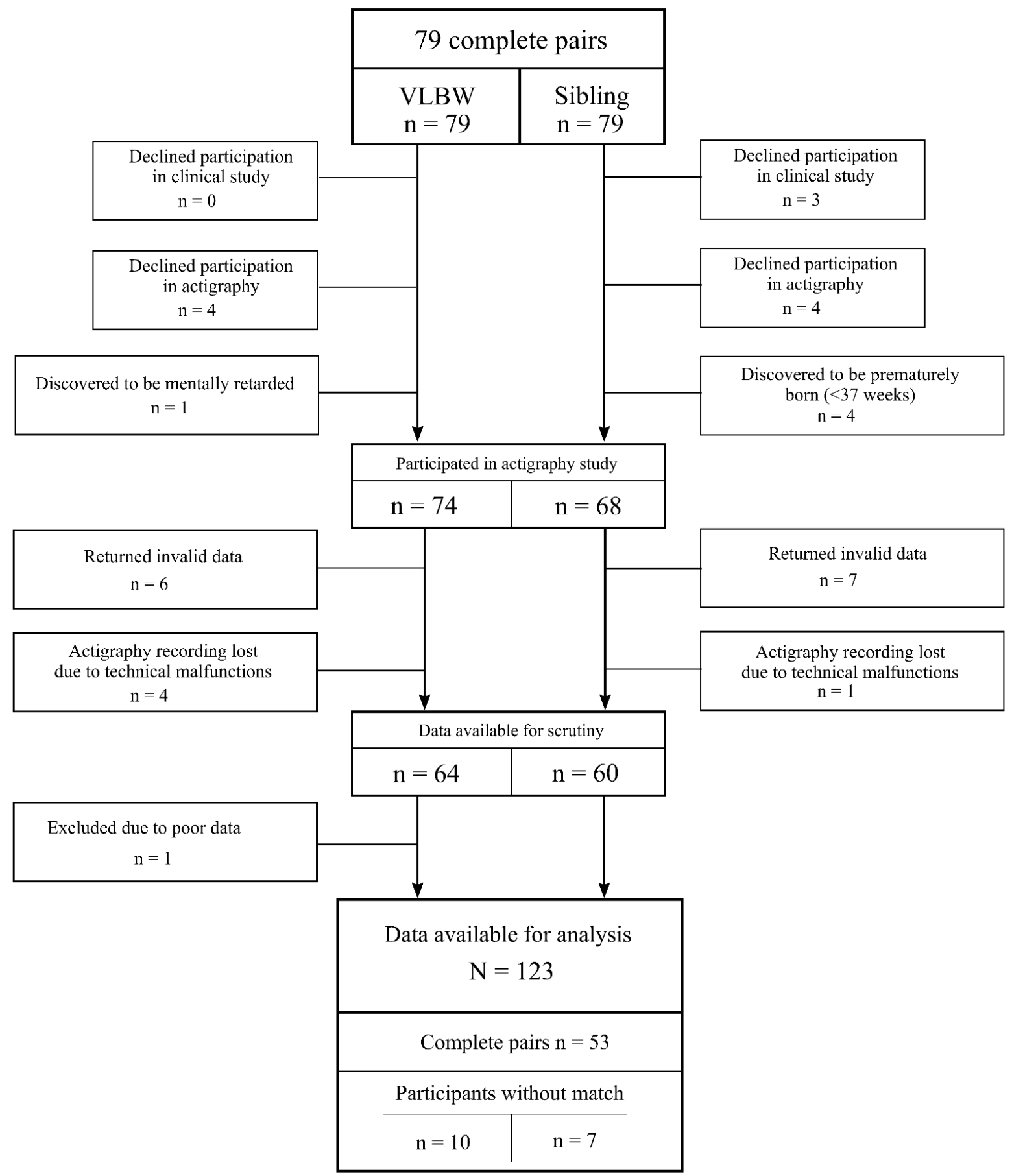




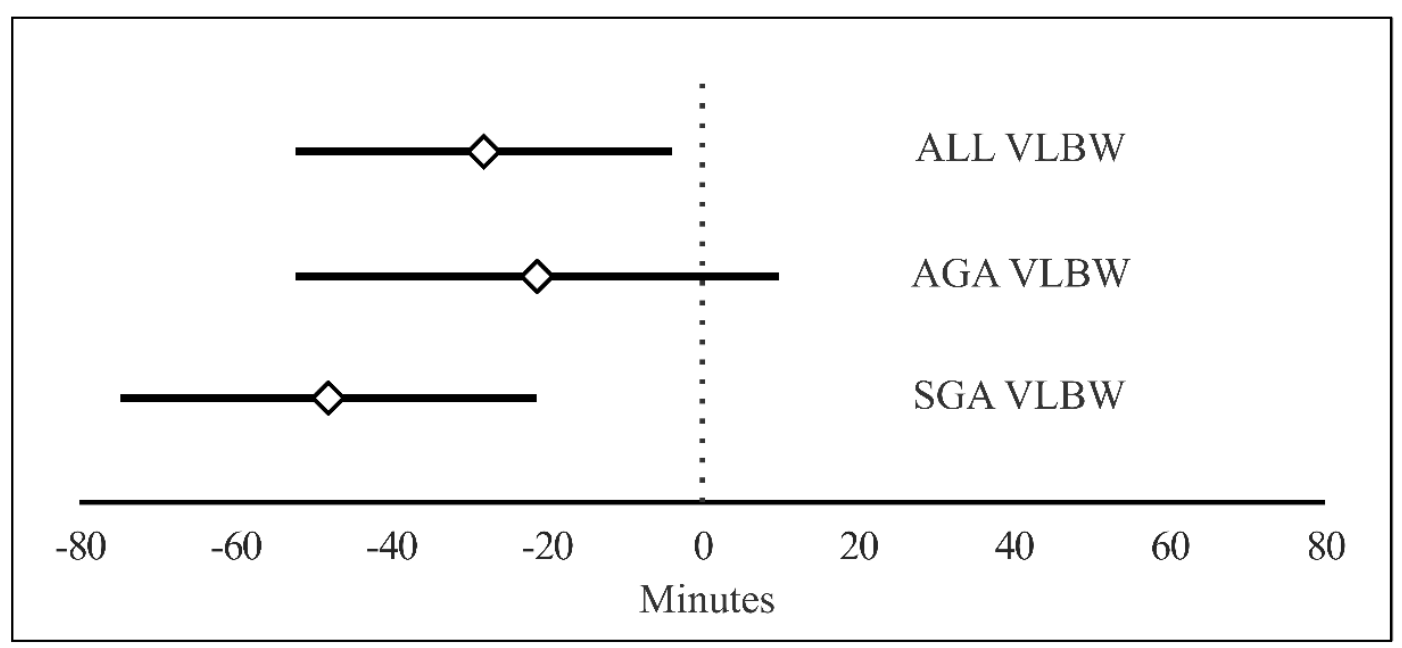

Figure 4 